\title{
PROGRAMAÇÃO DE COMPUTADORES E PROCESSOS AUXILIARES DA APRENDIZAGEM: O CASO DA ESCOLA DE HACKERS
}

\author{
COMPUTER PROGRAMMING AND THE AUXILIARY PROCESSES OF LEARNING: \\ HACKERS SCHOOL CASE
}

\section{PROGRAMACIÓN DE COMPUTADORAS Y PROCESOS AUXILIARES DE APRENDIZAJE: EL CASO DE LA ESCUELA DE HACKERS}

\author{
Fernanda Batistela ${ }^{1}$, Adriano Canabarro Teixeira ${ }^{2}$
}

\begin{abstract}
RESUMO
Em um mundo profundamente transformado pelas tecnologias de informática, o software assume papel estratégico de progresso humano e social. Nesse sentido, ganha força a percepção de que é fundamental ao cidadão contemporâneo adquirir habilidades de desenvolvimento de software e começam a se popularizar iniciativas que vão nessa direção. Dessa forma, este estudo tem como objetivo analisar o modo como a programação de computadores, foco do Projeto Escola de Hackers, influencia os processos auxiliares da aprendizagem. Isso, a partir de pesquisa de campo e do aporte teórico-pedagógico exposto por Juan Ignacio Pozo em sua obra "Aprendizes e Mestres: a nova cultura da aprendizagem". O referido Projeto, em atividade desde 2014, atende estudantes do Ensino Fundamental de escolas municipais da cidade brasileira de médio porte, Passo Fundo, Rio Grande do Sul, Ihes oportunizando atividades que conduzem ao aprendizado de técnicas e habilidades de programação através do software Scratch. Assim, este artigo é fruto do acompanhamento das atividades do Projeto em uma das escolas participantes junto a uma turma de 11 alunos. Os dados primários foram coletados por meio de observação, questionários e entrevistas e analisados a partir de categorias definidas em função do recorte teórico. Como resultado essencial, foi possível verificar que o processo auxiliar de aprendizagem que obteve mais destaque para o grupo de estudo foi a motivação.
\end{abstract}

PALAVRAS-CHAVE: Conhecimentos de informática. Processos auxiliares de aprendizagem. Tecnologia educacional. Recursos educacionais. Cultura contemporânea.

\section{ABSTRACT}

In a world profoundly transformed by computer technology, software plays a strategic role on human and social progress. In this sense, the force of recognition is fundamental for the evolution of software development. Thus, this study had computer programming as its goal, focus of the School of Hackers project, influenced by auxiliary learning processes. That is, a field research and a theoretical-pedagogical exposition by Juan Ignacio Pozo in his work "Apprentices and Masters: a new culture of learning". The project, which has been in operation since 2014, is held at the Basic Education Center of the Brazilian High School, in Porto Alegre, Rio Grande do Sul, with the learning of didactic practices and skills of apprentices through the Scratch software. Thus, this paper is the result of the activities promoted by the project in one of the participating schools, with a class of 11 students. The primary data were collected through observation, questionnaires and interviews and were used for formatting

\footnotetext{
${ }^{1}$ Mestre em Educação - Universidade de Passo Fundo (UPF) - Passo Fundo, RS. Brasil - Doutoranda em Educação - Universidade de Passo Fundo (UPF) - Passo Fundo, RS. Brasil. Coordenadora Pedagógica - Universidade de Passo Fundo (UPF) - Passo Fundo, RS. E-mail: batistela.fernanda@gmail.com

2 Doutorado em Informática na Educação - Universidade Federal do Rio Grande do Sul (UFRGS) - Rio Grande do Sul, RS. Brasil. Professor Titular - Universidade de Passo Fundo (UPF) - Passo Fundo, RS. Brasil. E-mail: teixeira@upf.br
}

Submetido em: 16/06/2016 - Aceito em: 07/05/2018

(C) ETD-Educação Temática Digital Campinas, SP $\quad$ v.20 $\quad$ n.3 $\quad$ p. $844-861 \quad$ jul./set. 2018


as a function of the theoretical cut. As an essential result, it was possible to verify the auxiliary learning process that was most important for the study group was the motivation.

KEYWORDS: Computer skills. Auxiliary learning processes. Educational technology. Educational Resources. Contemporary culture.

\section{RESUMEN}

En un mundo profundamente transformado por la tecnología informática, el software desempeña un papel estratégico en el progreso humano y social. En este sentido, la fuerza del reconocimiento es fundamental para la evolución del desarrollo de software. Por lo tanto, este estudio tuvo como objetivo la programación de computadoras, foco del proyecto School of Hackers, influenciado por procesos de aprendizaje auxiliares. Es decir, una investigación de campo y una exposición teóricopedagógica de Juan Ignacio Pozo en su obra "Aprendices y Maestros: una nueva cultura de aprendizaje". El proyecto, que ha estado en operación desde 2014, se lleva a cabo en el Centro de Educación Básica de la Escuela Superior de Brasil, en Porto Alegre, Rio Grande do Sul, con el aprendizaje de prácticas didácticas y habilidades de aprendices a través del software Scratch. Por lo tanto, este documento es el resultado de las actividades promovidas por el proyecto en una de las escuelas participantes, con una clase de 11 estudiantes. Los datos primarios se recolectaron mediante observación, cuestionarios y entrevistas, y se usaron para formatear en función del corte teórico. Como resultado esencial, fue posible verificar que el proceso de aprendizaje auxiliar que fue más importante para el grupo de estudio fue la motivación.

PALAVRAS-CLAVE: Conocimientos de informática. Procesos auxiliares de aprendizaje. Tecnología educativa. Recursos educativos. Cultura contemporánea.

\section{INTRODUÇÃO}

É possível verificar a crescente importância que os dispositivos tecnológicos computacionais têm assumido no processo de desenvolvimento humano, seja em uma perspectiva individual, social, política ou cultural. Embora os avanços na área de hardware, eficiência energética, sensores e na miniaturização tenham sido importantes no mundo contemporâneo, o vetor de inovação depende de forma predominante dos softwares. Essa dependência por softwares se amplia quando se considera os movimentos tecnológicos na área de Internet das Coisas e Big Data.

Nos contextos de educação formal e não-formal não somente o uso de softwares por si só, mas a sua produção e, em especial, a linguagem de programação é tida como um potencial recurso para a mobilização do sistema cognitivo. Autores como Papert (1994), Santaella (2004), Bonilla (2005) e Veen e Vrakking (2009) já empreenderam esforços consideráveis para compreender a relação entre o universo do educando, inserido num contexto tecnológico digital em uma sociedade da informação, e o seu desenvolvimento cognitivo, envolvendo habilidades e competências diversas. Nessa mesma direção, destacamse os estudos de Juan Ignacio Pozo, especialmente os tidos em sua obra "Aprendizes e Mestres: a nova cultura da aprendizagem" (POZO, 2002).

Juan Ignacio Pozo formou-se em Psicologia pela Universidade Autônoma de Madri, em 1980 e fez seu Doutoramento em Psicologia, pela mesma Universidade, em 1986. É

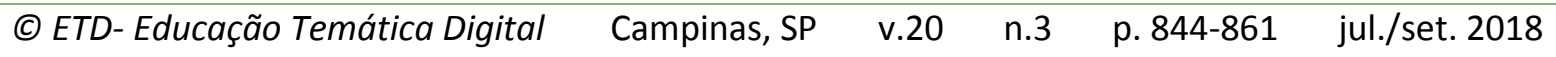


pesquisador construtivista, focado em diversos domínios do conhecimento, como história, geografia, ciências, gramática e, em especial, em estratégias cognitivas de aprendizagem. Tem publicado muitos documentos, artigos e livros que, na sua maioria, estão relacionados diretamente à aprendizagem. $\mathrm{O}$ autor a entende como um processo psicológico num contexto não somente ligado à escola, mas em um âmbito geral em que se ensina e em que se aprende.

Assim, Pozo frisa que, possivelmente, o ser humano está produzindo aprendizagens, em maior ou menor grau, em todas as suas atividades ou comportamentos. Portanto, podese dizer que a aprendizagem é o resultado de uma prática, a qual pode ser de característica implícita, em que o ser humano age inconscientemente, ou explícita, geralmente originadas de atividades sociais. As "situações mais claras de aprendizagem são as que implicam uma aprendizagem explícita, as que supõe que alguém, seja um professor ou o próprio aluno, organiza ou planifica atividades com o propósito deliberado de aprender" (POZO, 2002, p. 65). Contudo, independentemente dessas características e das teorias da aprendizagem humana, Pozo afirma que o ser humano aprende quando há consciência da mudança de seus conhecimentos e comportamentos anteriores.

De um modo geral, conforme o referido autor, para compreender os processos relacionados às atividades da aprendizagem, é necessário situá-las, primeiramente, no contexto social em que foram geradas, em sua história. Em épocas passadas, a aprendizagem era reprodutiva e os alunos escreviam e reescreviam até memorizar tal conteúdo para reproduzi-lo com facilidade. Esse tempo não pode ser comparado com as demandas da nova cultura da aprendizagem, tanto em qualidade como em quantidade. Essa perspectiva atual, enfatizada por Pozo no decorrer de sua obra, pressupõe que o ser humano aprenda cada vez mais, mais coisas. Segundo o autor, "jamais houve uma época em que tantas pessoas aprendessem tantas coisas distintas ao mesmo tempo, e também tantas pessoas dedicadas a fazer com que outras pessoas aprendam" (POZO, 2002, p.32), o que caracteriza a sociedade da aprendizagem.

Com tais entendimentos, Pozo (2002) propõe que a nova cultura da aprendizagem depende de importantes recursos cognitivos. Para o autor, a motivação, a atenção, a recuperação, a transferência das representações presentes na memória dos sujeitos e a consciência, são os quatro principais processos auxiliares que devem ser mobilizados para que ocorram aprendizagens significativas. Nessa direção, uma das teses que Pozo desenvolve é a de que toda situação de aprendizagem sempre implicará distintos tipos de resultados, processos e condições. Para isso, é necessário aceitar que ele é dotado de sistemas de memória interconectados. Ou seja, nessa nova sociedade, composta por um turbilhão de informações, a memória do ser humano acaba por reconstruir as informações que recebe, mais do que registrá-las, reproduzi-las ou, servir como arquivo cultural, no sentido tradicional. A memória é um dos componentes que integram os processos cognitivos da psicologia. Esses,

$\begin{array}{llllll}\text { (C) ETD- Educação Temática Digital } & \text { Campinas, SP } & \text { v.20 } & \text { n.3 } & \text { p. 844-861 } & \text { jul./set. } 2018\end{array}$


integrados a uma combinação de outros processos auxiliares influenciam de diferentes formas e em diferentes situações de aprendizagem, dependendo de seus objetivos e condições.

No âmbito deste trabalho, identificou-se de que forma a programação de computadores pode se constituir em um espaço de manifestação dos processos auxiliares de aprendizagem propostos por Pozo. Situando ainda mais, interessa especificamente o processo de programar e não o resultado da programação. Segundo Jeannette Wing (2006, p. 34), programar desenvolve o pensamento computacional, pois "involves solving problems, designing systems, and understanding human behavior, by drawing on the concepts fundamental to computer science".

Embora as primeiras experiências com programação de computadores por crianças remontem à década de 60 , nos últimos anos a temática tem voltado às pautas de discussão na área de informática educativa. Dentre as inúmeras iniciativas existentes ao redor do mundo com vistas ao ensino de programação para crianças e adolescentes, destaca-se a realizada em Passo Fundo, cidade de médio porte do estado do Rio Grande do Sul, Brasil, denominada Escola de Hackers. Essa atende a alunos e professores do 6으 ao 9o ano das escolas públicas municipais e, desde 2014, já formou mais de 700 crianças. O Projeto consiste em um conjunto de ações que oportunizam o aprendizado de técnicas e habilidades de programação, através do software Scratch.

No âmbito do projeto Escola de Hackers, acredita-se que os processos auxiliares da aprendizagem - motivação, atenção, recuperação e transferência e, ainda, consciência, segundo Pozo (2002), são mobilizados como processos influenciados pela experiência de programação. Isso, tanto pela ação dos monitores que conduzem as atividades mediando o conhecimento como pela interação entre os sujeitos-alunos. Essa mobilização do sistema cognitivo, segundo o autor, é essencial para que um indivíduo aprenda. Nesse sentido, o problema desta pesquisa assim se constrói: em que medida a programação de computadores, foco do Projeto Escola de Hackers, ativa os processos auxiliares da aprendizagem propostos por Juan Ignacio Pozo? Posto isso, este estudo teve por objetivo analisar a forma como a programação de computadores, foco do Projeto Escola de Hackers, influencia os processos auxiliares da aprendizagem expostos por Pozo (2002): motivação, atenção, recuperação e transferência e, ainda, a consciência.

\subsection{Processos auxiliares de aprendizagem}

Com a intenção de ampliar o entendimento sobre os processos da aprendizagem que ocorrem no ser humano, em especial, entre os 11 alunos participantes do projeto Escola de Hackers, num contexto novo de escola, com a utilização da programação de computadores, optou-se por evidenciar os quatro processos auxiliares da aprendizagem. Assim, discorre-se

$\begin{array}{llllll}\text { (C) ETD-Educação Temática Digital } & \text { Campinas, SP } & \text { v.20 } & \text { n.3 } & \text { p.844-861 } & \text { jul./set. } 2018\end{array}$


sobre a motivação, a atenção, a recuperação e transferência e a consciência, para servirem de lastro de análise dos dados da pesquisa de campo.

Particularizando-se cada um dos processos, principia-se pela motivação como primeiro intento auxiliar da aprendizagem elencado pelo autor, tendo por principais formas de manifestação os motivos, as expectativas e a intervenção. Segundo Pozo (2002), aprender implica ter motivos, sejam eles extrínsecos ou intrínsecos. A primeira forma acontece quando o "motivo da aprendizagem não é o que se aprende, mas as consequências de tê-lo aprendido" (POZO, 2002, p. 139). Ou seja, a aprendizagem é percebida quando o indivíduo foca nas consequências de seu aprendizado (motivação extrínseca). Por outro lado, quando o aluno desvia do resultado e foca na atividade de aprender em si, no desejo de aprender, isso constitui-se em um pressuposto que caracteriza a motivação intrínseca.

Para além desses fatores, a motivação depende também da expectativa de sucesso que o indivíduo espera ou tenta alcançar. Assim, ao perceber que suas expectativas não estão sendo alcançadas, sua motivação decresce e poderá não se esforçar mais para alcançar dado objetivo. Então, além de valorizar os progressos percebidos na aprendizagem dos indivíduos, existem dois caminhos para incrementar a motivação e colaborar para a aprendizagem: aumentar as expectativas e ampliar o valor do sucesso esperado. Por fim, a motivação depende da intervenção. Essa ocorre, segundo Pozo, quando a aprendizagem se relaciona com situações que os indivíduos precisam resolver, identificadas como problemas. "Perceber algo como um problema exige uma 'motivação' do aprendiz para a tarefa, para além das recompensas que receba por fazê-la bem" (POZO, 2002, p.254).

Em continuidade, a atenção é o segundo processo auxiliar da aprendizagem considerado por Pozo (2002). Suas principais formas de manifestação são os mecanismos de controle de recursos limitados, de seleção da informação que deve ser processada e, ainda, da vigilância ou alerta, que permite sustentar a atenção. "As três funções do sistema atencional (controle, seleção e vigilância) podem se tornar mais efetivas na aprendizagem se nós, professores, ajudarmos os alunos a seguir certos princípios" (POZO, 2002, p.150). Esse processo da aprendizagem está estreitamente ligado à memória de trabalho, a qual necessita ser ativada para que o indivíduo consiga processar as informações mais relevantes e lembrálas futuramente.

Já considerados os processos auxiliares de motivação e atenção, o próximo a ser compreendido é a recuperação e a transferência. Para Pozo (2002), suas principais formas de manifestação são por reconhecimento ou por evocação da aprendizagem para contextos novos. O reconhecimento é percebido no momento em que o indivíduo recupera, por si só e de alguma forma, uma aprendizagem que já aconteceu. A evocação, por sua vez, ocorre quando, em uma situação mais difícil - frente a muitas variáveis e poucos indícios que o

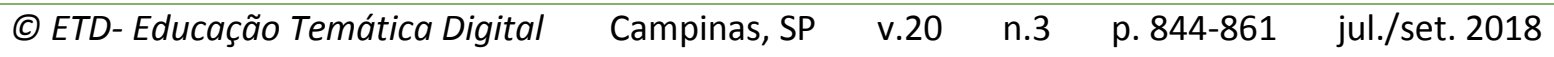


remetem à aprendizagem a ser recuperada - o indivíduo recebe um estímulo que o auxilia no recobramento da informação. Pozo (2002, p.152) diz que o reconhecimento antecede a evocação e apresenta um exemplo para explicar os dois processos:

\begin{abstract}
nos abarrotados corredores do supermercado, nos chocamos com outro carrinho que casualmente está sendo conduzido por uma pessoa em quem, de modo imediato, reconhecemos um antigo colega de trabalho. A presença de um estímulo ou uma configuração estimar (o cavanhaque e os óculos de aro de tartaruga) nos fazem recuperar uma representação adquirida desse estímulo, que traz consigo associada ou conectada outra informação (afinal, você montou o escritório? O que aconteceu com Helena, sua namorada naquele tempo? Você sabe alguma coisa sobre o Raul, sim, aquele que colava em todos os exames?).
\end{abstract}

Por fim, considerar a recuperação da aprendizagem remete a pensar a transferência. Essa "é uma das características centrais da boa aprendizagem e, portanto, um de seus problemas mais habituais" (POZO, 2002, p.63). A aprendizagem efetivamente só acontece quando o sujeito aprendente consegue não só recuperá-la, mas transferi-la, em outro momento, em outro local, em novos contextos. Conforme o autor, a capacidade de transferência demonstra que a aprendizagem aconteceu, pois, o indivíduo recupera uma informação e adapta-a a uma nova situação.

Trazidos a luz os processos auxiliares de motivação, atenção e recuperação/transferência, o próximo a ser compreendido é a consciência. Assim, a partir de Pozo (2002), refere-se que suas principais formas de manifestação são por meio de três tipos de controle mencionados - o planejamento da tarefa, a regulagem de sua execução e a avaliação de seus resultados. O planejamento pressupõe a organização de situações rotineiras (em que o ser humano não fixa metas para colocá-las em prática) e de situações não rotineiras (em que, ao se deparar com problemas, o indivíduo acaba elaborando um plano estratégico para guiar suas atividades). Desse modo, o planejamento de uma tarefa de aprendizagem "implica fixar, antes de começá-la, as metas e os meios para alcançá-la" (POZO, 2002, p. 160).

Concomitantemente, a regulagem vem acompanhar o planejamento, ou seja, além das metas estabelecidas, traçam-se submetas, as quais servirão para regular a própria prática e corrigir os possíveis erros ou desvios. A partir disso, é possível detectar incoerências que, em tempo, podem ser revistas, garantindo uma melhor estratégia. Segundo Pozo (2002, p. $160)$, as submetas são "pequenos 'marcos' que indicam que vamos na direção correta ". Por fim, o terceiro fator que impacta a tomada de consciência diz respeito à avaliação dos resultados alcançados. Momento em que o indivíduo vai refletir sobre suas formas de aprender, de acordo com as metas e submetas traçadas. Além disso, pode avaliar as incongruências de suas estratégias, ou seja, em que medida ou de que forma sua consciência fez certas coisas, utilizando-se de processos automatizados e controlados, uma vez que o ser humano só consegue destinar seus recursos cognitivos para uma parte dos estímulos. Dessa

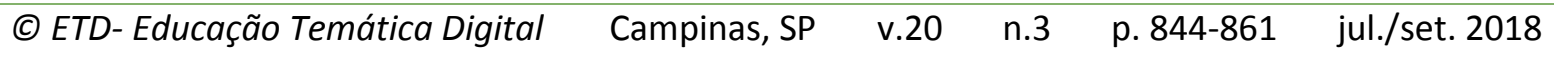


forma, o indivíduo faz um juízo sobre as próprias produções, procedendo a uma autoavaliação, "componente essencial do autocontrole em todo tipo de tarefas de aprendizagem" (POZO, 2002, p. 161).

Ante o entendimento dos quatro processos auxiliares - a motivação, a atenção, a recuperação e transferência e a consciência-, importa ressaltar que cada um apresenta características próprias, no entanto, se complementam entre si. Juntos, proporcionam ao indivíduo uma maior aprendizagem, que reflete numa maior consciência do próprio funcionamento cognitivo. Como afirma Pozo (2002, p. 138) "aprender requer mobilizar esse sistema cognitivo mediante múltiplos processos", e fazer um bom uso deles é produto de suas combinações. Feita essa síntese, é fundamental que se explore brevemente o contexto social sobre o qual a pesquisa se debruça no que se refere ao papel da informática educativa, ao perfil do estudante do século XXI e os desdobramentos do ato de programar em si.

\subsection{A programação de computadores como experiência de aprendizagem}

Juan Ignacio Pozo, em suas obras, deixa claro que nunca houve na história da humanidade uma sociedade composta por tão grande número de pessoas aprendendo em tamanha proporção e concomitantemente. Portanto, identifica-a como sociedade da aprendizagem, pois exige que o ser humano esteja sempre em busca de aprender mais coisas e de formas diferentes. Uma destas formas para aprender é por meio da informática que, por si só, é educativa, além disso, o contexto social contemporâneo aponta para uma tendência de impossibilidade de existência de educação sem informática.

Partindo do ponto de vista de sua contextualização, a informática educativa, mais especificamente, o computador, segundo Valente (1999), surgiu com a intenção primordial de resolver os problemas em cursos de pós-graduação e como máquina de ensinar, a partir de sua capacidade de programação. Fazendo-se uma correlação entre essa perspectiva e a popularização dos computadores pessoais com relação à época em que este estudo foi realizado, passaram-se mais de cinco décadas. Dentre as diferentes formas de apropriação dos computadores nesse período, pode-se afirmar que se passou de uma situação onde os indivíduos assumiam uma postura de usuários de computador para uma em que esses têm a possibilidade real de programá-los. Essa nova condição deveria ser uma habilidade de domínio comum, uma vez que auxilia no desenvolvimento de competências cognitivas como preconiza este estudo.

Papert (1985), na sua experiência com a linguagem LOGO, criada em 1967, afirma que os indivíduos criam, pensam, inventam, experimentam por meio da programação. Também, que usam o animal cibernético, identificado por uma tartaruga, para movimentá-lo conforme o próprio comando, o que os faz agirem de forma autônoma, planejarem, regularem e
(C) ETD- Educação Temática Digital
Campinas, SP
v. 20
n.3
p. $844-861$
jul./set. 2018 
avaliarem as próprias construções de conhecimento. Embora se esteja falando de um tempo transcorrido há mais de 51 anos, a referência ao LOGO é fundamental, uma vez que se trata da primeira experiência de fôlego no sentido de explorar os desdobramentos da programação de computadores para crianças. Além do que, a discussão da programação de computadores na educação tem ganhado força nos últimos anos em função do domínio que os jovens demonstram no manuseio das tecnologias. Posto isso, muito provavelmente uma das únicas atividades que podem ser propostas aos alunos nos laboratórios de informática escolares, que possa de fato desafiá-los, é a programação de computadores.

Nessa direção, Douglas Rushkoff (2012, p.20) ratifica a importância da programação de computadores, em especial no século XXI, enfatizando que o programar "significa determinar os códigos e as regras por meio das quais nossas muitas TICs construirão o futuro". Ou seja, o indivíduo que nasceu nesta era possui as habilidades do aluno do século XXI e possui autonomia para criar as próprias regras, as quais, segundo o autor, atribuirão reflexos futuros à sua vida no mundo. Caso isso não aconteça, então, o ser humano estará fadado às limitações do computador e ficará à mercê de ser programado por ele.

Pozo (2004) afirma ser importante formar alunos dotados de capacidades de aprendizagem, capazes de construir suas verdades particulares dentre tantas parciais. Também, salienta a essencialidade de que estejam preparados para usarem essas informações de forma estratégica e assimilarem-nas de forma crítica. Segundo o referido autor, usar as informações de forma estratégica consiste em convertê-las em um saber ordenado e em conhecimento verdadeiro. Além disso, na sociedade da informação em que se vive, são poucos os que conseguem ter acesso a esse modo de produzir conhecimento, a maioria permanece no âmbito de apenas assimilá-los e reproduzi-los.

Bonilla (2005), em convergência às ideias de Pozo, diz que, quando o indivíduo se sente desafiado, ele acaba buscando, sem a ajuda de outras pessoas, as melhores formas para criar, fazer e propor tarefas, o que influencia na transformação de informações em conhecimentos. Enfatiza, ainda, que esse processo faz parte do primeiro mecanismo ou função do sistema atencional, também relacionado por Pozo, que o divide em processos controlados (com atenção) e automatizados (sem atenção). Nessa perspectiva, Pozo (2002) diz que, quando o indivíduo consegue fazer as coisas sem a ajuda de outras pessoas é porque não precisa mais de "muletas".

Pozo (2002) compara esse processo de aprendizagem, pautado no protagonismo e na autonomia, à construção de uma obra, em que, primeiramente, os professores colocam "andaimes", ou seja, emprestam sua consciência ao aluno. Aos poucos, tais mestres vão retirando esses suportes, de forma que o aluno consiga ter consciência de si mesmo e não precise mais de tais "muletas". Salienta-se, conforme o referido autor, que quando o aluno

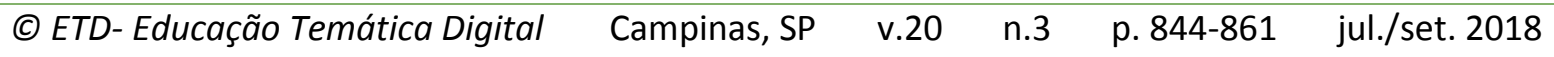


não precisa mais desses aparatos, é porque conseguiu tomar consciência do próprio funcionamento cognitivo. Portanto, ele consegue planejar suas tarefas, regular suas atividades de execução e refletir sobre suas produções, ou seja, avaliar seus resultados.

Quando estiver programando, o indivíduo estará continuamente buscando comandos adequados para a situação que pretende programar. Assim, exige-se a ativação da capacidade criadora e autônoma, pois estará constantemente testando suas aprendizagens. Agindo dessa forma, não terá suas respostas como certas ou erradas, mas sim, como resolvidas, pois conseguiu fazer a programação acontecer como desejava. Com o tempo, o indivíduo que programa estará apto a fazer suas escolhas independentemente e, por conseguinte, ter mais consciência sobre as próprias aprendizagens e de seu papel no mundo.

Diante do exposto percebe-se que o interesse educacional da programação de computadores decorre não só da sua importância econômica, mas também do seu valor como um ambiente de aprendizagem. Pode-se explorar a programação de computadores para o desenvolvimento de habilidades como resolução de problemas, pensamento criativo, raciocínio lógico, experimentação sistemática. Também, recentemente, como forma de alfabetização, para uma sociedade moderna, em que a programação se insere como disciplina escolar obrigatória, pois permite que os cidadãos se tornem ativos produtores de conteúdo digital interativo para web, facilitando o processo de aprendizagem (FESAKIS; SERAFEIM, 2009).

Conclui-se que $o$ ato de programar computadores está profundamente ligado aos processos cognitivos envolvidos no ato de aprender. Segundo Papert (1994), programar softwares favorece a aprendizagem pois dá autonomia ao estudante. Ainda, afirma que "a melhor aprendizagem ocorre quando o aprendiz assume o comando" (op. cit., 41), ou seja, quando ele possui o controle sobre a construção do seu conhecimento. Para isso, necessariamente, o sujeito usufruirá dos quatro processos auxiliares da aprendizagem e suas formas de manifestação.

Afora o LOGO, uma das ferramentas mais populares para a aprendizagem de programação é o Scratch. Trata-se de um sistema de programação desenvolvido pelo Instituto Tecnológico de Massachusetts (MIT), experiente no desenvolvimento de ferramentas educativas para crianças na idade escolar e pelo grupo Kids da Universidade de Califórnia em Los Angeles. Foi fundado por Mitchel Resnick, diretor, no MIT, de um grupo chamado Lifelong Kindergarten ( Jardim de Infância ao Longo da Vida). O Scratch tem sido adotado largamente em experiências de ensino de programação por possuir produtos específicos para diferentes públicos. Por exemplo, o Scratch Jr., que foi criado para crianças de cinco a oito anos, o Schatch, utilizado nesta pesquisa, e, ainda, o Scratch for Arduíno, adaptado para trabalhar robótica e, portanto, com sujeitos que já dominam o Scratch.
(C) ETD- Educação Temática Digital
Campinas, SP
v. 20
n.3
p. $844-861$
jul./set. 2018 
Diante das possibilidades representadas por esse sistema e do fato de que quando o aluno cria algo que é significativo, ele constrói o próprio conhecimento, pode-se retomar as ideias de Pozo (2002), para inferir que o uso do Scratch e, por conseguinte, da programação de computadores, possibilita um controle sobre a aprendizagem. Isso, pois ao desenvolver as habilidades necessárias para o manejo de tal ferramenta, o sujeito toma consciência do próprio funcionamento cognitivo e acaba distanciando-se cada vez mais do limite de apenas acatar às informações do professor, sem significá-las. Essa conduta, pressupõe que o sujeito aprendente faça uso ou esteja na dependência de um ou mais processos auxiliares de aprendizagem, ou seja - da motivação, da atenção, da recuperação e transferência e da consciência. Diante dessa constatação, na sequência apresenta-se o método utilizado para analisar o modo como a programação de computadores influencia os processos auxiliares da aprendizagem em uma amostra de alunos do Projeto Escola de Hackers

\section{MÉTODO}

Identifica-se esse estudo como exploratório, pois, segundo Gil (2007, p.43), sua principal finalidade é "desenvolver, estabelecer e modificar conceitos e ideias, tendo em vista, a formulação de problemas mais precisos ou hipóteses pesquisáveis para estudos posteriores". Delineia-se, também, como qualitativo, pois, conforme Bogdan e Biklen (1994), uma das características desse direcionamento está no processo para chegar até o resultado. Baseando-se nesses pressupostos, optou-se pelo uso de dois procedimentos técnicos: a) a pesquisa bibliográfica (especialmente para a produção de dados secundários); e, b) o estudo de caso (para a produção empírica de dados primários). Para esse último direcionamento, utilizou-se de uma triangulação de métodos de coleta de dados - a observação, a aplicação de questionários e a condução de entrevistas.

A observação, não participativa, ocorreu em diversos momentos e de vários modos semanalmente durante os meses de fevereiro a dezembro de 2014 durante as oficinas, pela leitura das fichas de cadastro dos alunos e das memórias de aula das monitoras. Ainda, procedeu-se à observação da amostra de pesquisa em suas turmas no contexto escolar tradicional. Por fim, destaca-se a observação realizada pela participação em reuniões junto à comissão organizadora do Projeto.

Para além das observações, utilizou-se do questionário aplicado mensalmente durante o tempo de pesquisa à equipe diretiva da Escola e, ainda, às monitoras do grupo amostrado. Em complemento, realizou-se uma entrevista com a equipe diretiva, a coordenadora do laboratório de informática, as professoras de Português e Matemática das turmas, a monitora do grupo e os alunos participantes - no início e no final do Projeto.

A escola escolhida para a efetivação deste estudo faz parte da rede pública de ensino

$\begin{array}{llllll}\text { (c) ETD-Educação Temática Digital } & \text { Campinas, SP } & \text { v.20 } & \text { n.3 } & \text { p. } 844-861 & \text { jul./set. } 2018\end{array}$


do município e atende 420 alunos. O principal motivo dessa escolha deve-se ao fato de que se trata da Escola piloto do Projeto Escola de Hacker. Para sigilo das informações, identificouse por letras todos os sujeitos envolvidos na pesquisa e aplicou-se um Termo de Consentimento Livre e Esclarecido. A seleção dos 11 alunos do 8ㅇ e 9o anos do Ensino Fundamental que representam a amostra deste estudo foi realizada pela equipe diretiva das escolas. Definida a amostra de estudo, aplicou-se as atividades no laboratório de informática da escola, em duas horas semanais, no turno inverso às atividades escolares.

\subsection{A organização dos dados primários coletados}

O primeiro momento de organização dos dados primários coletados, caracterizou-se pela descrição fidedigna desses considerando o que foi observado, lido ou escutado por meio dos instrumentos já informados. Optou-se pelo registro descritivo, em documentos separados de acordo com cada tipo de recurso. Posteriormente, planejou-se a metodologia para a distribuição de tais dados, em consonância com as categorias de análise (processos auxiliares) e subcategorias (suas formas de manifestação). Assim sendo, antecipando-se à futura análise dos resultados e com a intenção de apresentar os elementos balizadores da coleta, elaborou-se uma tabela, resumidamente representada a seguir (Tabela 1), composta por questionamentos retidos da obra de Pozo (2002) sobre os processos cognitivos da aprendizagem.

TABELA 1: Parte dos questionamentos para a distribuição dos dados

\begin{tabular}{|c|c|c|}
\hline Categoria & $\begin{array}{l}\text { Forma de } \\
\text { manifestação }\end{array}$ & Questionamento \\
\hline \multirow[t]{3}{*}{ Motivação } & Motivos & $\begin{array}{l}\text { O aluno está aprendendo por motivos extrínsecos, ou seja, pela } \\
\text { satisfação de aprender? } \\
\text { O aluno está aprendendo por motivos intrínsecos, ou seja, para evitar } \\
\text { algo indesejado ou para conseguir algo desejado, em troca de } \\
\text { aprender? }\end{array}$ \\
\hline & Expectativa & $\begin{array}{l}\text { O aluno está esperando de si próprio, expectativa de sucesso ou de } \\
\text { fracasso? } \\
\text { Os outros esperam que este aluno tenha sucesso ou fracasso? } \\
\text { O aluno está se esforçando para alcançar um resultado? }\end{array}$ \\
\hline & Intervenção & $\begin{array}{l}\text { Pensando nos seis princípios, apontados por Pozo, conforme Tabela } \\
7 \text {, as monitoras estão intervindo, de alguma forma, na motivação dos } \\
\text { alunos? }\end{array}$ \\
\hline
\end{tabular}

Fonte: [Autores].

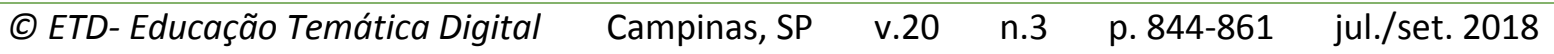


Com tal sistematização, seguiu-se para o segundo momento de registro dos dados, com a criação de documentos direcionados individualmente para cada uma das quatro categorias de análise. Feito isso, observando-se de forma simultânea os questionamentos, iniciou-se o processo de distribuição de dados coletados entre as tabelas. Cada informação foi nomeada como 'manifestação' e o número de repetições como 'percepção'. Após o mapeamento de todos os indícios de ocorrência das categorias, somou-se o número de vezes que foram percebidas, o que possibilitou o direcionamento da análise para o processo auxiliar com maior incidência.

O número de percepções torna-se significativo, pois responde à pergunta de pesquisa, mostrando qual dos processos cognitivos de Pozo (2002) se destaca diante do contexto de Escola de Hackers. Assim, oportuniza uma análise mais pormenorizada e complexa do fenômeno observado. Desse modo, contabilizou-se 1065 percepções, que resultou em uma Tabela de Controle das Análises (Tabela 2), que contemplou cada categoria de análise (motivação, atenção, recuperação e consciência) e suas formas de manifestação: motivação (motivos (M), expectativa $(E)$, intervenção $(I)$ ), atenção (controle $(C)$, seleção $(S)$, vigilância $(V)$ ), recuperação (reconhecimento $(R)$, evocação $(E)$, transferência $(T)$ ), e, consciência (planejamento $(\mathrm{P})$, regulagem $(\mathrm{R})$ e avaliação $(\mathrm{A})$ ). Ainda, a Tabela 2 apresenta a distribuição dos dados na pesquisa em campo e a soma de todos esses valores.

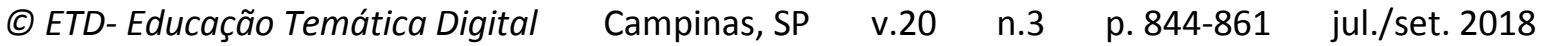


TABELA 2: Controle das análises

\begin{tabular}{|c|c|c|c|c|c|c|c|c|c|c|c|c|c|}
\hline \multirow{2}{*}{$\frac{\text { Dados coletados }}{\text { Observações }}$} & \multicolumn{3}{|c|}{ MOTIVAÇÃO } & \multicolumn{3}{|c|}{ ATENÇÃO } & \multicolumn{3}{|c|}{ RECUPERAÇÃO } & \multicolumn{3}{|c|}{ CONSCIÊNCIA } & \multirow[b]{2}{*}{ SOMA } \\
\hline & $M$ & $\mathbf{E}$ & 1 & C & $S$ & $\mathbf{V}$ & $\mathbf{R}$ & $E$ & $\mathbf{T}$ & $\mathbf{P}$ & $\mathbf{R}$ & A & \\
\hline $28 / 05$ & 3 & 4 & 1 & 4 & 4 & 0 & 1 & 0 & 2 & 1 & 0 & 0 & 20 \\
\hline $04 / 06$ & 9 & 8 & 3 & 10 & 10 & 0 & 4 & 0 & 4 & 6 & 4 & 4 & 62 \\
\hline $11 / 06$ & 7 & 7 & 0 & 3 & 4 & 0 & 2 & 0 & 2 & 3 & 3 & 3 & 34 \\
\hline $18 / 06$ & 6 & 9 & 4 & 5 & 1 & 0 & 2 & 1 & 3 & 2 & 2 & 3 & 38 \\
\hline $25 / 06$ & 6 & 8 & 3 & 4 & 2 & 0 & 3 & 1 & 2 & 2 & 2 & 2 & 35 \\
\hline 09/07 & 6 & 6 & 7 & 7 & 2 & 1 & 3 & 2 & 4 & 3 & 2 & 3 & 46 \\
\hline $16 / 07$ & 5 & 5 & 0 & 2 & 2 & 1 & 1 & 1 & 1 & 1 & 1 & 1 & 21 \\
\hline $20 / 08$ & 10 & 9 & 5 & 1 & 2 & 0 & 3 & 0 & 2 & 1 & 1 & 1 & 35 \\
\hline $27 / 08$ & 12 & 13 & 2 & 7 & 0 & 0 & 6 & 0 & 5 & 1 & 3 & 4 & 53 \\
\hline 03/09 & 5 & 5 & 1 & 5 & 6 & 5 & 3 & 2 & 1 & 3 & 2 & 2 & 40 \\
\hline $17 / 09$ & 5 & 4 & 0 & 2 & 4 & 1 & 1 & 0 & 1 & 2 & 0 & 0 & 20 \\
\hline $22 / 10$ & 9 & 10 & 3 & 10 & 11 & 3 & 4 & 3 & 3 & 3 & 2 & 3 & 64 \\
\hline $29 / 10$ & 6 & 6 & 6 & 3 & 2 & 1 & 1 & 1 & 1 & 2 & 2 & 1 & 32 \\
\hline $12 / 11$ & 2 & 2 & 0 & 3 & 3 & 1 & 1 & 0 & 1 & 2 & 1 & 1 & 17 \\
\hline $19 / 11$ & 4 & 4 & 1 & 5 & 5 & 2 & 2 & 0 & 1 & 1 & 1 & 1 & 27 \\
\hline $26 / 11$ & 6 & 6 & 6 & 5 & 5 & 0 & 3 & 0 & 3 & 2 & 0 & 0 & 36 \\
\hline $02 / 12$ & 4 & 4 & 3 & 3 & 3 & 2 & 2 & 0 & 1 & 3 & 0 & 0 & 25 \\
\hline Entrevistas & 56 & 91 & 4 & 35 & 24 & 3 & 25 & 9 & 22 & 8 & 16 & 28 & 321 \\
\hline Questionários & 7 & 7 & 0 & 6 & 6 & 0 & 3 & 0 & 4 & 3 & 3 & 0 & 39 \\
\hline $\begin{array}{c}\text { Percepções/ } \\
\text { monitores }\end{array}$ & 13 & 20 & 8 & 10 & 15 & 1 & 9 & 0 & 9 & 6 & 5 & 4 & 100 \\
\hline \multirow[t]{2}{*}{ SOMA } & 181 & 228 & 57 & 130 & 111 & 21 & 79 & 20 & 72 & 55 & 50 & 61 & \multirow[t]{2}{*}{1065} \\
\hline & \multicolumn{3}{|c|}{466} & \multicolumn{3}{|c|}{262} & \multicolumn{3}{|c|}{171} & \multicolumn{3}{|c|}{166} & \\
\hline
\end{tabular}

Fonte: [Autores].

A partir dessa organização dos dados em categorias de análise, mediante um universo de processos cognitivos da aprendizagem, chegou-se aos resultados dessa pesquisa. Sempre se mantendo o foco na análise da forma como a programação de computadores, atividade precípua do Projeto Escola de Hackers, influencia os processos auxiliares da aprendizagem da amostra de pesquisa em questão, de acordo com Juan Ignacio Pozo. Em face à gama de resultados produzidos, descreve-se neste artigo apenas aqueles referentes à categoria com maior número de percepções, ou seja, a motivação.

\section{RESULTADOS}

A pesquisa analisou um contexto da Escola de Hackers, representado por 11 alunos do 8ㅇ e 9o anos do Ensino Fundamental de uma escola pública, piloto para o Projeto. Assim, verificou-se, a partir da Tabela 2, um resultado de 1065 percepções correspondentes aos quatro processos auxiliares da aprendizagem e suas formas de manifestações. Do total de
(C) ETD- Educação Temática Digital
Campinas, SP
v. 20
n. 3
p. $844-861$
jul./set. 2018 
percepções, 466 (44\%) reportam à motivação como fator de maior influência na aprendizagem da programação, ativada por motivos internos (intrínsecos) e/ou externos (extrínsecos). Em segunda colocação aparece a atenção, com 262 percepções (25\%), restando a recuperação, com 171 percepções (16\%) e a consciência com o menor número de percepções, totalizando 166 (15\%), conforme Gráfico 1.

GRÁFICO 1: Resultados da categorização dos processos auxiliares de aprendizagem

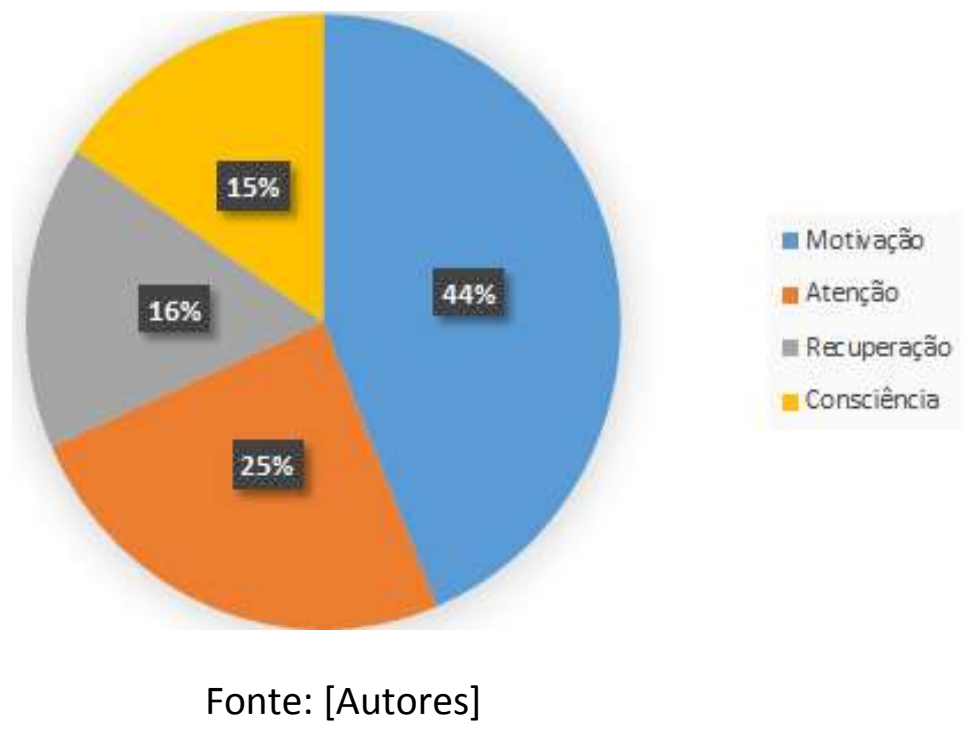

Apresenta-se brevemente os resultados apresentados no Gráfico 1 relacionando-os a luz do referencial teórico. Referindo-se à atenção, constatou-se que os aprendizes nem sempre concentraram seus recursos no que era mais relevante, ou seja, nos três mecanismos necessários para processar as informações: "um sistema de controle de recursos limitados, um mecanismo de seleção ou filtro da informação que deve ser processada e um mecanismo de alerta ou vigilância, que permite manter ou sustentar a atenção" (POZO, 2002, p.146). Em relação à recuperação, provavelmente ocorreu o que Pozo identifica como um dos problemas de aprendizagem mais difíceis de superar, pois o indivíduo pensa que aprendeu alguma coisa, porém, ao se deparar com uma situação nova, que requer a utilização de seus conhecimentos, não consegue recuperá-los. Por fim, os resultados relativos à consciência refletem que o sistema cognitivo humano dos participantes não foi " capaz de adquirir consciência de si mesmo, de regular sua própria atividade e de refletir sobre suas próprias produções" (POZO, 2002, p. 157), ao ponto de ser superior à motivação.

Ante ao exposto, retoma-se o Gráfico 1 para novamente destacar que a motivação foi o processo auxiliar da aprendizagem que mostrou o maior número de percepções, por meio de suas subcategorias: motivos, expectativa e intervenção. Dentre essas, como expressa o Gráfico 2, destacou-se as 228 percepções de motivação por expectativa (49\%), seguida de 181

$\begin{array}{llllll}\text { (C) ETD- Educação Temática Digital } & \text { Campinas, SP } & \text { v.20 } & \text { n.3 } & \text { p. } 844-861 & \text { jul./set. } 2018\end{array}$ 
percepções por motivos (39\%). Em menor quantidade revelaram-se 57 percepções de motivação por intervenção (12\%).

GRÁFICO 2: Resultados do processo auxiliar de aprendizagem motivação em subcategorias

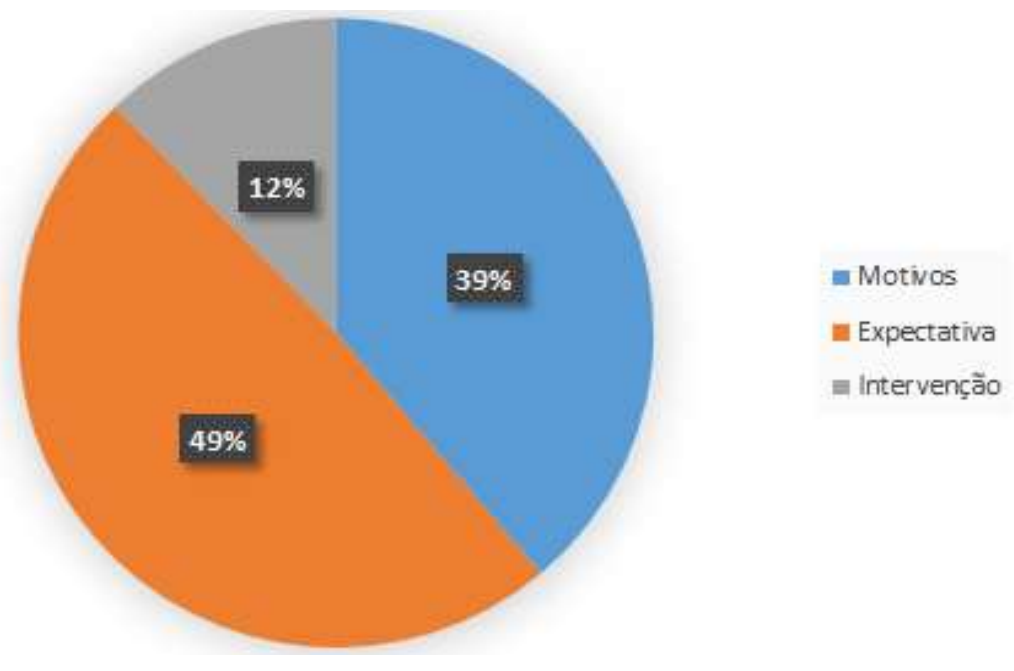

Fonte: [Autores]

Pautando-se tais resultados na teoria que conduz esta análise (POZO, 2002), percebese que a preponderância da motivação por expectativa ancora-se, especialmente, na possibilidade de rendimento do próprio aluno. Exemplifica-se tal direcionamento, a partir da transcrição de um trecho da entrevista com alunos, quando uma das alunas participantes do projeto afirmou que participar dele "é mais divertido do que eu imaginava. Já se passaram seis meses, mas não parece, parece que o tempo não passa de tão rápido. No início eu tinha muito medo de não saber as coisas, e eu fui evoluindo com o tempo, hoje eu ajudo os outros". De outro aluno depreende-se ter gostado "muito do assunto, da programação, gostei muito de aprender a programar, eu nem sabia que existia esse programa, o Scratch, achei legal aprender". Ou seja, quando o aluno mostra que está aprendendo de forma que sua motivação pode decrescer ou aumentar, dependendo do sucesso que ele espera de si mesmo se tentar alcançá-lo ou pelo sucesso que os outros esperam dele, ele está motivado pela expectativa.

Nessa direção se apresentam outros desdobramentos que se destacaram, como a manifestação do aluno que "esperava que fosse mexer mais no sistema", atividade para a qual demonstrava muito interesse. Mesmo assim, disse que foi compensado: "no início eu achei que era aquilo lá, mexer no computador, mas depois fui começando a aprender e se tornou divertido, daí eu comecei a gostar do curso". Percebe-se que o aluno refletiu sobre si mesmo e através de seu processo auxiliar consciência, foi capaz de fazer uma avaliação do próprio programa.

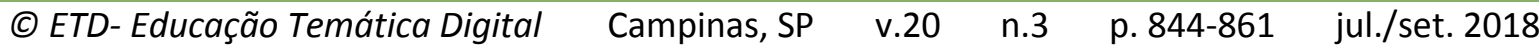


Foi possível, também, por meio das 1065 percepções, descobrir que dentre todos os dados coletados nesta pesquisa, nos dias 22 de outubro, quatro de junho e 27 de agosto, destacados na Tabela 2, os alunos mostraram maior número de manifestações de aprendizagens. Nessa ordem, obteve-se uma soma de 64, 61 e 55 percepções, o que representa um número superior ao registrado nas demais oficinas observadas. Considerando-se essas três oficinas de forma especial, percebeu-se que foram realizadas dinâmicas de integração entre os participantes. Assim, permite-se inferir que os alunos se motivam mais quando há momentos de maior interação, por meio de dinâmicas que extrapolem somente o uso do Software Scratch e do computador, tendo cada aluno concentrado em seu equipamento e em suas programações.

Ressalta-se como importante, ainda, o fato de um aluno afirmar que conseguiu "ter mais concentração e consegui fazer as coisas mais sozinho, não dependendo muito dos outros. Minha mãe reclamava porque eu não tinha paciência. Agora ela falou que sou mais calmo, mais paciente". Outro depoimento é de uma aluna, que afirma ter desenvolvido "bem mais o raciocínio, de você ler e entender, você tá fazendo as coisas, você tem que pensar antes pra chegar em algum lugar, e isso ajudou bastante". Na mesma direção apontam as entrevistas com professores "eles tiveram mais concentração em sala de aula, a grande maioria, mas eles tiveram rendimento na área de matemática, concentração maior nesta área aí; encontraram um pouco mais de responsabilidade; evoluíram bastante na atenção; se tornaram mais participativos, mais ativos para fazer as atividades; e esses alunos tem mais habilidade eu diria" na área de língua portuguesa. Os alunos também perceberam tais desdobramentos, como registrado na fala de um aluno, a qual aprendeu "a fazer textos, tinha muita dificuldade agora estou conseguindo fazer".

Chama-se atenção para uma última reflexão, percebida na fala de uma aluna: "na programação, é que a gente vai testando o programa sempre, se não dá certo, a gente acha uma forma de corrigir ele, e lá no Scratch ele mostra o que não tá funcionando" e "a gente aprender cada vez mais, daí a gente percebe os erros". Essa fala vem ao encontro ao que Papert (1985) afirma, quando diz que uma característica relevante da programação de computadores é que a criança dificilmente vai acertar na primeira vez que programar, então, ela vai persistindo e resolvendo os problemas até chegar ao resultado que pretende. Tal direcionamento, diferentemente do modelo de educação tradicional em que existe o acertou e o errou e retarda a aprendizagem de muitas crianças, possibilita seu protagonismo e sua evolução cognitiva. Assim, todos aprendem por meio dos próprios erros ou pelo dos seus colegas, portanto, quem programa acaba se tornando mais tolerante com relação aos seus erros e, consequentemente, mais motivado. 


\section{CONSIDERAÇÕES FINAIS}

A busca essencial deste estudo foi a de analisar a forma como a programação de computadores, foco do Projeto Escola de Hackers, influencia os processos auxiliares da aprendizagem - motivação, atenção, recuperação e transferência, consciência - expostos por Juan Ignacio Pozo em sua obra "Aprendizes e Mestres: a nova cultura da aprendizagem". Assim, após um processo de pesquisa bibliográfica e estudo de campo (utilizando-se a triangulação de instrumentos de produção de dados primários: observação, questionário e entrevistas), foi possível identificar a presença dos quatro processos.

Percebeu-se que os alunos foram motivados, ou por si mesmos, ou pela interferência das monitoras, a estimularem seus processos auxiliares da aprendizagem. Ainda, que eles ativaram o primeiro mecanismo do sistema atencional por meio dos processos controlados e não somente dos automatizados; impulsionaram o processo de motivação, por fatores internos ou externos, bem como esperaram alcançar o sucesso em suas atividades. Também, recuperaram e transferiram seus aprendizados para contextos novos, por meio da evocação ou pelo reconhecimento, muitas vezes, passando por distorções, achando que lembravam, quando, na verdade, não recordavam suas aprendizagens.

Ante ao exposto, afirma-se que os 11 alunos, a partir da participação no Projeto Escola de Hackers e, em especial, das percepções das doze subcategorias nascidas dos quatro processos auxiliares da aprendizagem propostos por Pozo (2002). Esses, construíram o próprio conhecimento sobre programação de computadores, em vez de se limitar a dar significados ao que receberam das monitoras, ou seja, os alunos, através do processo auxiliar consciência, passaram a refletir sobre suas ações.

Aponta-se outros desdobramentos importantes da programação de computadores, emergidos a partir do estudo. Dentre esses a contribuição para o desenvolvimento do raciocínio lógico nas disciplinas escolares, em especial na Matemática e Língua Portuguesa, quando percebeu-se mais consciência sobre as ações e mais calma para realizar as atividades. Afirma-se, também, que os alunos passaram a planejar suas atividades e, depois, efetivá-las e avaliá-las. Conseguiram, dessa forma, pensar no processo da aprendizagem e não somente focar no resultado. Em esforço de síntese, conclui-se que dentre todos os aspectos relevantes observados, a motivação, especialmente por expectativa, foi a categoria que se destacou como processo auxiliar de aprendizagem proporcionado pela participação do sujeito aprendente no Projeto Escola de Hackers.

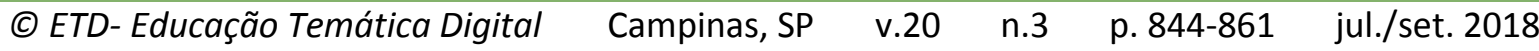




\section{REFERÊNCIAS}

BONILLA, Maria Helena Silveira. Escola aprendente: para além da sociedade da informação. Rio de Janeiro, RJ: Quartet, 2005.

BOGDAN, Robert; BIKLEN, Sari. Investigação qualitativa em educação: fundamentos, métodos e técnicas. In: Investigação qualitativa em educação. Portugal: Porto Editora, 1994. p. 15-80.

FESAKIS, Georgios; SERAFEIM, Kiriaki. Influence of the familiarization with "scratch" on future teachers' opinions and attitudes about programming and ICT in education. Inroads SIGCSE Bulletin, n. 41, p. 258-262, 2009. Doi: 10.1145/1595496.1562957.

GIL, Antonio Carlos. Métodos e técnicas de pesquisa social. 5. ed. São Paulo: Atlas, 2007.

PAPERT, Seymour. Logo: computadores e educação. Trad. Ernani Rosa. São Paulo, SP: Brasiliense, 1985.

PAPERT, Seymour. A máquina das crianças: repensando a escola na era da informática. Porto Alegre, RS: Artes Médicas, 1994.

POZO, Juan Ignácio. Aprendizes e mestres: a nova cultura da aprendizagem. Porto Alegre, RS: Artmed, 2002.

POZO, Juan Ignácio. A sociedade da aprendizagem e o desafio de converter informação em conhecimento. Revista Pátio, Porto Alegre, a. 8, ago./out. 2004. Disponível em: http://www.udemo.org.br/A\%20sociedade.pdf. Acesso em: 31 maio 2015.

RESNICK, Mitchel. Media Lab Video. 2007. Vídeos about Scratch: http://scratch.mit.edu. Disponível em: https://www.youtube.com/watch?v=knFykmLljos Acesso em: 26 abr. 2015.

RUSHKOFF, Douglas. As 10 questões essenciais da era digital: programe seu futuro para não ser programado por ele. São Paulo: Saraiva, 2012.

VALENTE, José Armando. O computador na sociedade do conhecimento [Versão Digital]. Campinas, São Paulo: UNICAMP/NIED, 1999. Disponível em:

http://www.fe.unb.br/catedraunescoead/areas/menu/publicacoes/livros-de-interesse-naarea-de-tics-na-educacao/o-computador-na-sociedade-do-conhecimento. Acesso em: 24 dez. 2014.

WING, Jeannette. Computational Thinking. Communications of the ACM, mar. 2006.

Revisão gramatical sob a responsabilidade de: Renata Confortin. Mestre em Educação. E-mail: confortinrenata@gmail.com 